\title{
RELAÇÕES ENTRE EVIDENCIAÇÃO DA EXISTÊNCIA DE CONTROLADORIA E CARACTERÍSTICAS DAS EMPRESAS LISTADAS NA B3
}

\begin{tabular}{|c|c|}
\hline Nome & Emily Tavares Pessoa Maciel \\
\hline URL & https://orcid.org/0000-0001-6304-6653 \\
\hline Instituição/Afiliação & Universidade Federal da Paraíba - UFPB \\
\hline País & Brasil \\
\hline Nome & Antônio André Cunha Callado \\
\hline URL & https://orcid.org/0000-0002-5704-9265 \\
\hline Instituição/Afiliação & Universidade Federal Rural de Pernambuco - UFRPE \\
\hline País & Brasil \\
\hline
\end{tabular}

\section{RESUMO}

O presente estudo objetivou analisar a significância das relações entre a existência da controladoria e as características das empresas listadas na B3. Foi realizada uma pesquisa exploratória, descritiva e quantitativa. Os dados coletados foram apresentados de maneira descritiva e posteriormente analisados através dos testes Qui-Quadrado, U de Mann-Whiteny e Kruskal-Wallis. A partir dos resultados obtidos, percebeu-se que o tempo médio de constituição das empresas é de 41 anos e ainda com relação às suas características, contam com uma média de 7.300 empregados. Também foi verificado que a receita de venda de bens e/ou serviços, número de empregados e número de empregados mais terceirizados se mostraram relacionados de maneira significativa à presença de unidade organizacional referente à controladoria na estrutura da organização.

Palavras-chave: Controladoria. Estrutura organizacional. Informações empresariais.

\begin{abstract}
The present study aimed to analyze the significance of the relationships between the existence of controllership and the characteristics of the companies listed on B3. An exploratory, descriptive and quantitative research was carried out. The collected data were presented in a descriptive manner and subsequently analyzed using the Chi-Square, U-Mann-Whiteny and Kruskal-Wallis tests. From the results obtained, it was noticed that the average time of constitution of the companies is 41 years and still with respect to their characteristics, they have an average of 7,300 employees. It was also verified that revenue from the sale of goods and/or services, number of employees and number of more outsourced employees were shown to be significantly related to the presence of an organizational unit related to controllership in the organization's structure.
\end{abstract}

Key words: Controllership. Organizational structure. Business information.

\section{INTRODUÇÃO}

As organizações têm buscado errar cada vez menos, atrair sucesso no seu mercado de atuação e atender aos desejos dos gestores, frente a esse contexto, desenvolveu-se a 


\section{Revista \\ UNEMAT de \\ Contabilidade}

v. 9 , n. 17,2020

controladoria, que assume papéis de controle, avaliação, comunicação, gerenciamento e de apoio a todos os gestores das organizações (PADOVEZE, 2013).

Para Nascimento e Reginato (2013) a controladoria, essencialmente, reporta informações à alta administração das organizações e interage com todos os funcionários da empresa, em torno dos seus objetivos, através de monitoramentos constantes, com o propósito de facilitar a gestão. A controladoria pressupõe a estipulação de metas, o tracejar dos caminhos para que seja possível atingir tais metas e posteriormente a exposição, aos membros da organização, até onde a organização conseguiu chegar, proporcionando que cada funcionário identifique a sua responsabilidade para a sustentabilidade da organização.

Compreende-se que a sustentabilidade empresarial, tão procurada pelas organizações, pode surgir do fornecimento de informações que advêm da controladoria, informações que sejam úteis para o processo decisório. É imprescindível destacar que as organizações buscam constantemente o avanço empresarial, medindo ações e controlando determinadas variáveis, com o propósito de avaliar o custo versus o benefício de tais escolhas, que não podem ser feitas de forma aleatória, mas sim de forma pensada e planejada (NASCIMENTO; REGINATO, 2013).

A controladoria tem sido impulsionada também pelos avanços tecnológicos, devido aos avanços da tecnologia os processos de gestão das organizações têm sofrido alterações, sempre com o propósito de conduzir as organizações ao êxito empresarial, e proporcionar-lhes um maior controle de suas ações.

Tem-se que face à inconsistência econômica nacional, dinamismo social, abertura de novos mercados e concorrência crescente, as organizações têm utilizado diversos meios para se manterem estáveis e conseguirem atingir suas metas. A controladoria auxilia os gestores no processo de tomada de decisão, fornecendo informações de controle e avaliação do desempenho da organização, contribuindo, então, para a sustentabilidade competitiva da entidade (LOURENSI; BEUREN, 2011).

Observa-se que a controladoria não veio apenas para auxiliar à contabilidade das organizações, mas para assistir toda a organização, desde a alta administração, aos níveis hierárquicos mais baixos da estrutura da organização. As estruturas das organizações nada mais são do que as representações das atividades realizadas por cada organização, com o objetivo de organizar, dividir e coordenar as atividades das organizações (STONER; FREEMAN, 1985).

Uma estrutura organizacional bem delineada e uma controladoria bem aplicada trazem inúmeros benefícios ao contexto organizacional (MORANGE; JORGE, 2008). Com o 


\section{Revista \\ UNEMAT de \\ Contabilidade}

v. 9 , n. 17,2020

alinhamento da estrutura e a solidificação de uma controladoria as organizações conseguem identificar em quais níveis encontram-se os erros e onde devem estimular ou moderar as atividades.

Para que uma organização seja mais fidedigna com relação às suas informações, o uso de dados e o controle das suas operações, ela pode fazer uso das ferramentas e ideias advindas da controladoria.

Frente à essencialidade da controladoria e da estrutura organizacional a presente pesquisa busca analisar a significância existente das relações entre a evidenciação da controladoria e as características das organizações. O universo da pesquisa será as 426 empresas de capital aberto listadas na B3, segundo a Thomson Reuters Eikon®, em junho de 2019.

\section{REVISÃO DE LITERATURA}

\subsection{Controladoria}

A origem da controladoria está ligada ao processo de evolução dos meios de produção e sociais que ocorreram devido à Revolução Industrial. Alguns fatores são considerados os precursores para a sua origem: a globalização das empresas, o aumento em relação ao tamanho e à complexidade das empresas e o crescimento das relações governamentais (SCHMIDT; SANTOS, 2009).

O surgimento da controladoria foi impulsionado, além da Revolução Industrial, pelo crescimento geográfico, com o intuito de proporcionar controle às organizações, que almejavam expandir e garantir mercado. Para Lima, De Luca, Santos e Ponte (2011), a controladoria, portanto, busca assegurar a eficácia empresarial mediante o fornecimento de informações que auxiliem o processo decisório com o objetivo de proporcionar à organização resultados econômicos melhores.

Entende-se controladoria como o departamento que é responsável pelo projeto, pela elaboração, implementação e manutenção dos sistemas integrados de informações financeiras, operacionais e contábeis de uma entidade (OLIVEIRA; PEREZ; SILVA, 2015). O objeto de estudo da controladoria é, dessa forma, a informação e a mutação patrimonial (PADOVEZE, 2016).

A controladoria é essencialmente importante para a sobrevivência, a consolidação e o crescimento contínuo das organizações (MORANGE; JORGE, 2008). Ela exerce papel principal no processo de gestão e o seu desenvolvimento ocorreu frente a preceitos básicos da 


\section{Revista \\ UNEMAT de \\ Contabilidade}

v. 9, n. 17,2020

contabilidade (COELHO; LUNKES; MACHADO, 2012). Ela funciona como o navegador que cuida dos mapas da navegação, tendo como finalidade manter o comandante informado sobre as distâncias já percorridas, a localização, a velocidade, os desvios de rotas, os recifes perigosos e os caminhos pré-estabelecidos, para que o navio chegue ao destino (PADOVEZE, 2013).

Implementar as práticas de controladoria nas organizações é uma característica do contexto em que a organização está inserida (LEITE; DIEHL; MANVAILER, 2015). As práticas de controladoria precisam moldar-se à organização, seja no seu contexto externo seja no seu contexto interno, para que tenham êxito.

Leite, Reif e Lavarda (2018) inferem que a dinâmica do ambiente das organizações impulsiona a gestão delas, apontando que a alta competitividade, o surgimento constante de novas tecnologias, a mudança no perfil do gestores e também as exigências vindas por parte dos consumidores afetam diretamente as organizações, obrigando-as a se adaptarem ao meio em que estão inseridas e fazendo com que a controladoria, então, exerça essa função de direcionamento das organizações, tanto dos fatores internos quanto dos fatores externos às empresas. A controladoria não é estática, ela tende a mudar e se moldar frente às organizações que a utilizam.

O profissional responsável por exercer funções de controladoria é o controller, que precisa conhecer muito bem o funcionamento da cadeia de valor em que a organização está inserida, para que seja capaz de passar informações pertinentes aos seus superiores, a respeito dos seus fornecedores de recursos materiais, financeiros, tecnológicos e até informacionais, com o propósito maior de atingir a meta da organização (SCHMIDT; SANTOS; MARTINS, 2014).

Beuren, Gomes e Luz (2012) complementam que a função controller (sub) existe, independente das organizações possuírem ou não departamentos ou setores específicos de controladoria. A falta de conceituação concreta de quem seria o profissional controller é corriqueira, em grande parte da literatura; com as organizações, este fato também não é diferente.

A divergência sobre os conceitos dos temas discutidos até então dificulta o seu entendimento e nos força a compreender que qualquer um deles varia frente ao contexto e à situação em que está inserido. Dentre todas as literaturas vistas, se observou que a controladoria objetiva o controle das metas que pretendem ser atingidas pelas organizações, proporcionando informações necessárias aos gestores, enquanto o controller é o responsável pela execução de toda a controladoria descrita anteriormente. É o profissional competente para desempenhar o 


\section{Revista \\ UNEMAT de \\ Contabilidade}

v. 9, n. 17,2020

papel de orientar os gestores da empresa e fornecer informações necessárias para o sucesso e a sustentabilidade empresarial.

Nascimento, Rosa, Santos e Tenório (2005) apontam que a controladoria nada mais é do que um órgão da empresa que possui estrutura funcional formada por conceitos e por técnicas e tem por objetivo a geração de informações úteis e necessárias para a tomada de decisão dos gestores. A controladoria, então, não tem o intuito de apenas fornecer informações à entidade, mas de fornecer informações fidedignas e tempestivas.

A controladoria exerce grande importância no interior das organizações, analisando os dados para discutir os ramos que a organização precisará seguir e as tendências mercadológicas e organizacionais (ARAÚJO, 2003).

Segundo Callado e Amorim (2017) a controladoria responde pelo controle dos processos de gestão das organizações, utilizando da contabilidade e proporcionando informações a todos os setores das organizações, informações úteis para o processo decisório. Para Araújo (2003) a controladoria atua como um órgão de observação e controle, que tem como objetivo informar à alta administração as situações presente e futura da organização, identificando possíveis riscos e retornos para a empresa.

Para Peleias (2002), a controladoria é a área da organização que tem autoridade para tomar decisões sobre transações, eventos e atividades que forneçam suporte ao processo de gestão.

É importante frisar que a controladoria não é identificada em todas as organizações. Segundo Tung (2016), as empresas pequenas tendem a não contar com profissionais que tratem exclusivamente da controladoria; nas empresas menores, o que acontece é que o dono é o próprio controlador, gerente e responsável pelos assuntos jurídicos da empresa.

A prática da controladoria está difundida entre as organizações desde o início do século XX. Porém, o termo controladoria ainda não é completamente definido na literatura, mas diversos autores vêm tentando conceituá-lo (POLITELO; GUSE; LEITE; SULVA; DORR, 2014).

\subsection{Estruturas Organizacionais}

Conforme Stoner e Freeman (1985) as estruturas das organizações são as representações das atividades realizadas por cada organização, ou seja, é a forma como as organizações são divididas, organizadas e coordenadas, possibilitando também a visualização dos níveis decisórios da mesma. Mintzberg, Lampel, Quinn e Ghoshal (2011) e Montana e Charnov (2010) 


\section{Revista \\ UNEMAT de \\ Contabilidade}

v. 9, n. 17,2020

apontam que uma estrutura organizacional eficiente proporciona à organização um bom desempenho de suas tarefas.

A elaboração de uma estrutura organizacional não é simples, ela precisa refletir e ser útil para o contexto de cada organização. Na estrutura organizacional há a separação e conceituação dos cargos, perfis profissionais e os níveis hierárquicos adotados por cada organização (CARREIRA, 2009).

A estrutura organizacional objetiva tornar claro o padrão de coordenação de atividades realizados pela organização (ALMEIDA; MACHADO NETO; GIRALDI, 2006). Faz-se necessário destacar que a estrutura não surge nas organizações do nada, elas geralmente são desenvolvidas quando pontuado os propósitos específicos da empresa e o interesse dos gestores, que pode ser tanto para organizar o quadro de funcionários, delimitar funções, determinar metas ou nortear as ações de todos que fazem parte da organização.

Observa-se que manter as estruturas organizacionais definidas é essencial para o sucesso da organização; por meio da estrutura que é adotada é possível discriminar caminhos, orientar ações e tornar claro o papel que os funcionários desempenham no contexto organizacional, para todos os membros da instituição.

A estrutura organizacional, na visão de Mintzberg et al. (2011), acompanha a estratégia de forma concomitante; apesar de existirem de forma independente, tendem a influenciar uma a outra. A estrutura reflete o tipo de estratégia de jogo que a organização deseja estabelecer para alcançar seus objetivos e é essencial para a implementação e desenvolvimento do plano organizacional constituído pela organização (MEGGINSON; MOSLEY; PIETRI JR, 1998; OLIVEIRA, 2013).

Muitas vezes a relação entre a estratégia e a estrutura organizacional é estabelecida pelo ambiente externo, pois, corriqueiramente é necessário definir a estratégia para posteriormente pensar no design organizacional (GIRALDELI; PICCHIAI, 2015).

As estruturas organizacionais tendem a envolver fronteiras entre as partes interessadas de diferentes unidades organizacionais que podem ter várias formas. Inicialmente, as partes interessadas são organizadas pela sua função, posteriormente há a separação por unidade de negócios, com o propósito de otimizar e tornar eficientes os fluxos de trabalho dentro da unidade e, por fim, as unidades podem ser separadas pelo local, o que infere que haja uma necessidade de troca cuidadosa de dados e informações (KELLNER; RINGHOFER; HEHENBERGER; WEINGARTNER; FRIEDL, 2016). Percebe-se que independente de qual seja a forma de organização adotada pela organização, ela sofrerá influência do meio. 


\section{Revista \\ UNEMAT de \\ Contabilidade}

v. 9, n. 17,2020

As organizações e as estruturas organizacionais atuam como fatores essenciais que precisam ser considerados no processo estratégico da organização (MINTZBERG et al., 2011). $\mathrm{O}$ aumento da expectativa de clientes exige que as organizações busquem maiores níveis de eficiência e qualidade. Para isso, é essencial que sejam levantados dados sobre a história da empresa, qual sua natureza, tipo de atividade, serviços ofertados, entre outros, para que seja possível fazer um diagnóstico da organização e, posteriormente, a implementação da estrutura organizacional mais adequada (CARREIRA, 2009; SANTOS; BRONZO; OLIVEIRA; RESENDE, 2014).

Carreira (2009) afirma que não há comportamentos idênticos entre as empresas, visto que os seus valores variam, principalmente se tratando do cenário onde estão inseridas. Cada organização precisa elaborar o seu planejamento de forma individual, que precisa se moldar às suas necessidades e aspirações, levando em consideração a idade da organização, o tamanho e a atividade fim. Na perspectiva de Willaert, Berg, Willems e Deschoolmeester (2007), é essencial que a organização tenha uma visão holística sobre os seus processos, estruturas organizacionais, desempenho, cultura, vícios e crenças.

Sedimentar e reforçar as culturas, vícios e crenças das organizações também está associado ao tipo de cultura organizacional que é adotada pela entidade (LEITE; ALBUQUERQUE, 2009). É possível que a maioria dos processos e do desempenho da organização seja alterada, se a estrutura organizacional for modificada, visto que há uma relação muito próxima entre todas essas características da organização.

A estrutura organizacional, para Costa, Souza e Fell (2012) é apontada como essencial para todas as entidades, por contemplar os processos decisórios, níveis hierárquicos, comunicações verticais e horizontais.

Uma organização é constituída por elementos e estruturas, que combinadas geram as relações entre os elementos organizacionais (AHMADY; MEHRPOUR; NIKOORAVESH, 2016). Pode-se dizer então que a estrutura organizacional é a maneira ou método adotado por cada organização para dividir, organizar e coordenar suas atividades.

Para Costa, Souza e Fell (2012) as organizações precisam adotar processos de estruturação, para atender aos pedidos do mercado. Os processos apontados pelos autores, segundo Oliveira (2013), são processos dinâmicos e não estáticos, que precisam moldar-se sempre frente ao mercado e à especificidade das pessoas que fazem parte de cada estrutura organizacional. Oliveira (2014) apontou que as organizações que permitem receber influências 


\section{Revista \\ UNEMAT de \\ Contabilidade}

v. 9, n. 17,2020

positivas do mercado tendem a ser as organizações que mais contribuem, positivamente, no desenvolvimento do objetivo da entidade.

É imprescindível que as organizações observem o ambiente em que estão inseridas, pesando e ponderando todas as suas ações, a fim de delinear sua estrutura e traçar suas metas levando-o em consideração. Percebe-se que a organização recebe inúmeras intervenções, sejam diretas, identificadas mais facilmente pela organização, seja interferências indiretas.

Um receio das organizações que desejam se expandir e crescer, focando na estrutura organizacional, é de se expor às ameaças ambientais em novos mercados ou mercados já fortalecidos, que ainda não haviam sido confrontadas antes (BELMIRO; OLIVEIRA; AZEVEDO; LAGE, 2014). A dúvida do sucesso organizacional muitas vezes retrai as organizações e limitam as suas ações.

\section{METODOLOGIA}

\subsection{Tipologia da pesquisa}

A presente pesquisa se caracteriza como exploratória, descritiva e quantitativa, respondendo aos questionamentos propostos, principalmente sobre os indícios de existência ou não da controladoria nas empresas pesquisadas. A pesquisa começa com a característica exploratória, pelo fato de existirem apenas ideias vagas, nada concretas, relacionadas ao tema e posteriormente caracteriza-se como descritiva por buscar descrever como um grupo específico se comporta (SAMPIERI; COLLADO; LUCIO, 2013).

Para Marconi e Lakatos (2017), a pesquisa descritiva tem como objetivo descrever as características das organizações e da população, enquanto a pesquisa exploratória complementa a descritiva, proporcionando uma maior familiaridade do pesquisador com o seu problema de pesquisa e com a construção dos seus objetivos.

Baptista e Campos (2018) constatam que a pesquisa descritiva objetiva descrever determinado grupo para identificar quais são as suas condições e queixas, não indo em busca de nexo causal nem buscando identificar relações de causa e efeito, mas buscando compreender a situação do universo pesquisado. Já Sampieri, Collado e Lúcio (2013) afirmam que os estudos exploratórios são realizados quando há o propósito de examinar um problema de pesquisa ou tema ainda pouco estudado, em que não há a presença de ideias concretas. 


\section{Revista

A característica exploratória da pesquisa se deu pela escassez de pesquisa relacionada ao tema que foi pesquisado, proporcionando uma maior familiaridade entre o assunto e o pesquisador.

As pesquisas quantitativas contam com um modelo de conhecimento chamado positivista, conclusivo, que objetiva quantificar um problema e entender a sua dimensão, prevalecendo a preocupação estatístico-matemática, já que conta com um problema de pesquisa delimitado e concreto, versando sobre questões específicas (LAKATOS; MARCONI, 2017; SAMPIERI; COLLADO; LUCIO, 2013).

Quanto à técnica de coleta de dados, utilizou-se a pesquisa documental, que se utiliza de fontes secundárias, que fazem surgir os dados secundários que podem ser encontrados em arquivos como editoriais, leis, atas, listas, correspondências, escritas, entre outros (BAPTISTA; CAMPOS, 2018; RAMPAZZO, 2015). Ainda segundo Rampazzo (2015), a pesquisa documental apresenta vantagens principalmente por constituir uma fonte rica e estável de dados, não só por responder definitivamente um problema, mas por proporcionar uma melhor visão desse problema.

$\mathrm{Na}$ pesquisa, foram analisados os websites das empresas listadas na Brasil, Bolsa e Balcão (B3), os documentos lá inseridos e todas as informações pontuadas como úteis para a pesquisa, no período de junho a setembro de 2019.

$\mathrm{O}$ universo da pesquisa compreendeu todas as 426 empresas, listadas no site da B3, que é a Bolsa de Valores oficial do Brasil, com sede em São Paulo, e foi considerada em 2017 como a quinta maior bolsa de mercado de capital e financeiro do mundo.

Definir quais as variáveis utilizadas na pesquisa é de suma importância. A variável tende a ser considerada uma classificação ou uma medida que é adotada pelo pesquisador (MARCONI; LAKATOS, 2019).

As variáveis são, portanto, as características que o pesquisador determina como essenciais a pesquisa. Para Appolinário (2016), as variáveis trazem consigo certos atributos como nome, definição, escopo e ordenação.

Com o propósito de atingir o objetivo da pesquisa para analisar a significância das relações entre a evidenciação da presença (ausência) de controladoria no âmbito da estrutura organizacional das empresas listadas na B3, foi considerado o seguinte grupo de variáveis: 


\section{Contabilidade}

Quadro 1 - Variáveis relacionadas às informações prestadas pela empresa.

\begin{tabular}{|c|c|}
\hline \multicolumn{2}{|c|}{ Grupo I - Informações sobre as empresas } \\
\hline Variável & Escala de mensuração \\
\hline Tempo de constituição & Numérica \\
\hline $\begin{array}{c}\text { Tempo de registro na CVM - Comissão de Valores } \\
\text { Mobiliários }\end{array}$ & Numérica \\
\hline Receita de venda de bens e/ou serviços & Numérica \\
\hline Número de empregados & Numérica \\
\hline Número de empregados + terceirizados & Numérica \\
\hline Disponibilização de organograma & Binária \\
\hline Estrutura do organograma & Binária \\
\hline
\end{tabular}

Fonte: Elaborado pelos autores (2019).

Com o propósito de atingir o objetivo da pesquisa, foi elaborado um checklist, que contemplava todas as variáveis, seguido das suas opções possíveis, para identificar nos documentos das empresas pesquisadas.

A pesquisa utilizou do método quantitativo para a análise dos dados, em específico dos instrumentos estatísticos. O método quantitativo se destaca pela importância da garantia na precisão dos resultados, evitando distorções de análises e interpretações, bem como as inferências que possam ser feitas (BEMFICA, 2016).

Nas pesquisas quantitativas, o pesquisador busca expressar quais as relações que existem entre as variáveis, identificando os elementos básicos e pontuando a evolução das relações entre os distintos elementos. Tal metodologia apresenta as vantagens do controle das variáveis, a verificação dos resultados por meio de análises estatísticas e também evita a subjetividade do pesquisador (LAKATOS; MARCONI, 2017).

A operacionalização da pesquisa se deu mediante a utilização da estatística descritiva e inferencial. A estatística descritiva, segundo Silva, Silva, Gonçalves e Murolo (2018), tem as atribuições de obtenção, organização, redução e representação dos dados estatísticos, como também a obtenção de algumas informações que auxiliem a descrição do fenômeno que está se estudando.

Utilizaram-se os testes não paramétricos de $U$ de Mann-Whiteny, pela presença de variáveis dicotômicas, de mensuração ordinal, aplicados em amostras pequenas, que podem ter dimensões diferentes. Segundo Vieira (2011), o teste de Mann-Whiteny é utilizado com o propósito de se testar a hipótese de que duas populações apresentam distribuições iguais. $\mathrm{O}$ teste não paramétrico de Mann-Whiteny é flexível em relação às premissas de normalidade e homogeneidade das variâncias e compara dois grupos não pareados, com o propósito de identificar se pertencem ou não à mesma população (FÁVERO; BELFIO; SILVA; CHAN, 2009; CAVENAGHI; PIMENTA JÚNIOR; ANTÔNIO; LIMA; CORRÊA, 2019). 
O teste Qui-Quadrado é utilizado com o propósito de entender o nível de relação entre as variáveis estudadas. Para Spiegel e Stephens (2009) e Calzolaio, Spricigo e Monteiro (2018), o teste Qui-Quadrado pode ser utilizado para identificar a proximidade das distribuições teóricas, normais ou bonimiais, e se ajustam às distribuições empíricas, aquelas obtidas por meio dos dados amostrais. A técnica estatística em questão permite saber se na análise há um padrão de associatividade entre dados categóricos distintos, de forma simplificada, e se eles são independentes ou não.

O teste de Kruskal-Wallis também é um teste não paramétrico utilizado para testar se as amostras se originam da mesma distribuição, produzido exclusivamente para variáveis ordinais (MARÔCO, 2011). O teste de Kruskal-Wallis é um teste que analisa a variância da classificação de um critério ou experimento com um fator, podendo utilizar-se da generalização (SPIEGEL; STEPHENS, 2009). Com o teste de Kruskal-Wallis, há a possibilidade de testar se três ou mais amostras independentes foram extraídas de populações que apresentavam as mesmas médias (FÁVERO et al., 2009).

\section{APRESENTAÇÃO E ANÁLISE DOS RESULTADOS}

As variáveis foram analisadas, inicialmente, através dos resultados das suas estatísticas descritivas, retratadas a seguir.

A Tabela 1 retrata sobre os indícios da existência da controladoria, apontando o quantitativo de organizações que não contam com a unidade organizacional de controladoria, as que apenas citam, em todos os seus documentos disponíveis, que contam com a unidade organizacional de controladoria e o quantitativo de empresas que apresenta informações sobre tal controladoria:

Tabela 1 - Indícios da existência da controladoria

\begin{tabular}{ccc}
\hline & Frequência & \% \\
\hline Nada reportam sobre a controladoria & 206 & $48,36 \%$ \\
Só citam a controladoria & 123 & $28,87 \%$ \\
Disponibilizam informações sobre a controladoria & 97 & $22,77 \%$ \\
\hline & $\mathbf{4 2 6}$ & $\mathbf{1 0 0 , 0 0 \%}$ \\
\hline
\end{tabular}

Fonte: Dados da pesquisa.

Em relação à existência ou não da controladoria, 51,64\% das empresas (220 delas) relatam ter a unidade organizacional de controladoria, porém, grande parte dos 51,64\% $(28,87 \%)$ delas apenas aponta a existência e não discorre nada mais sobre; enquanto quase 


\section{Contabilidade}

metade das empresas, 206 empresas (48,36\%), não chega a citar a controladoria em nenhum dos seus documentos ou publicações nos sítios institucionais.

A Tabela 2 evidencia a primeira variável referente às informações das empresas, que se refere ao tempo de constituição delas, em anos:

Tabela 2 - Tempo de constituição da empresa

\begin{tabular}{cc} 
Média & 41 \\
Moda & 21 \\
Mediana & 31 \\
Desvio Padrão & 29,653 \\
Assimetria & 1,320 \\
Curtose & 2,713 \\
Mínimo & 3 \\
Máximo & 211 \\
\hline
\end{tabular}

Fonte: Dados da pesquisa.

Percebe-se que o tempo médio de constituição das empresas é de 41 anos e que a empresa mais nova a se constituir e fazer parte da B3 tem 3 anos de constituição, a Vert Companhia Securitizadora; já a empresa mais antiga tem 211 anos de constituição, o Banco do Brasil S.A.

A Tabela 3 traz o tempo de registro das empresas na CVM, média, moda, mediana, desvio padrão, assimetria, curtose, mínimo e máximo.

Tabela 3 - Tempo de registro na CVM

\begin{tabular}{cc} 
Média & 22 \\
Moda & 12 \\
Mediana & 19 \\
Desvio Padrão & 15,3817 \\
Assimetria & 0,7229 \\
Curtose & $-0,3932$ \\
Mínimo & 1 \\
Máximo & 76 \\
\hline
\end{tabular}

Fonte: Dados da pesquisa.

Identifica-se que o maior quantitativo de empresas, 47 empresas, se registrou na CVM no ano de 2007, certamente influenciado pela migração da Bovespa, que deixa de ser uma instituição sem fins lucrativos e se torna uma S.A. (Sociedade Anônima). 


\section{Contabilidade}

A Tabela 4 evidencia as informações sobre a receita de venda de bens e/ou serviços das empresas em reais, pesquisadas com o intuito de testar as relações do quantitativo de receitas, e outras variáveis da pesquisa.

Tabela 4 - Receita de vendas de bens e/ou serviços

\begin{tabular}{cc}
\hline Média & $11.587 .863 .398,51$ \\
Moda & $6.584 .936 .000,00$ \\
Mediana & $1.011 .894 .000,00$ \\
Desvio Padrão & $57.439 .458 .117,48$ \\
Assimetria & 9,9575 \\
Curtose & 117,3438 \\
Mínimo & $-417.879 .000,00$ \\
Máximo & $820.960 .883 .000,00$ \\
\hline
\end{tabular}

Fonte: Dados da pesquisa.

É importante apontar que apenas uma empresa, a GP Investments LTD., apresentou saldo negativo, o que se justifica um saldo negativo no valor mínimo referente às receitas obtidas pelas organizações.

A Tabela 5 apresenta informações da quantidade de empregados. Faz-se necessário destacar que algumas empresas pertencem à Categoria B da Bolsa, Brasil e Balcão e, por conseguinte, não têm a obrigatoriedade de divulgação dos números de funcionários e algumas outras empresas ainda afirmaram não terem empregados, como as holdings.

Tabela 5 - Número de empregados

\begin{tabular}{cc} 
Média & 7.305 \\
Moda & 0 \\
Mediana & 1.331 \\
Desvio Padrão & 18995,78 \\
Assimetria & 6,1926 \\
Curtose & 52,3787 \\
Mínimo & 0 \\
Máximo & 220.506 \\
\hline
\end{tabular}

Fonte: Dados da pesquisa.

No que se refere ao quantitativo de empregados, vê-se que as empresas, em sua maioria, contam com uma quantidade considerável de empregados, em média 7.304. A empresa que conta com o maior número de empregados, 220.506, é a JBS S.A. 


\section{Contabilidade}

A Tabela 6 evidencia o número de empregados mais terceirizados das empresas, que foi encontrado frente ao somatório do número de empregados com o número de terceirizados:

Tabela 6 - Número de empregados + terceirizados

\begin{tabular}{cc} 
Média & 10.054 \\
Moda & 0 \\
Mediana & 1.948 \\
Desvio Padrão & 26055,7781 \\
Assimetria & 5,1267 \\
Curtose & 30,4229 \\
Mínimo & 0 \\
Máximo & 233.388 \\
\hline
\end{tabular}

Fonte: Dados da pesquisa.

Observa-se que há uma pequena diferença entre as estatísticas descritivas dos empregados e dos empregados mais terceirizados. Percebe-se que há um aumento no quantitativo de empregados mais terceirizados, pelo acréscimo dos terceirizados. A moda e o mínimo continuam sendo 0 , frente às holdings, que afirmaram em seus relatórios/documentos que não contam com empregados como também não contam com terceirizados.

A Tabela 7 apresenta a frequência de organizações que disponibilizam ou não organograma:

Tabela 7 - Disponibilização de organograma

\begin{tabular}{ccc}
\hline & Frequência & \% \\
\hline Não disponibiliza & 324 & $76,06 \%$ \\
Disponibiliza & 102 & $23,94 \%$ \\
\hline & $\mathbf{4 2 6}$ & $\mathbf{1 0 0 , 0 0 \%}$ \\
\hline
\end{tabular}

Fonte: Dados da pesquisa.

No que diz respeito à disponibilização do organograma, 324 empresas (76,06\%), das 426 pesquisadas, não disponibilizam organograma em nenhum dos locais pesquisados (sites, formulário de referência, apresentações institucionais, relatórios anuais, ambientais, entre outros documentos disponibilizados pelas mesmas). As 102 empresas que disponibilizaram organograma, em sua maioria, o disponibilizaram no site.

Entre as 102 empresas $(23,94 \%)$ que disponibilizam organograma, pesquisou-se qual o tipo de estrutura, conforme a Tabela 8, as empresas apresentam.

Tabela 8 - Estrutura do organograma

\begin{tabular}{ccc}
\hline & Frequência & $\%$ \\
\hline Achatada & 1 & $0,98 \%$
\end{tabular}




\section{Contabilidade}

\begin{tabular}{ccc} 
Alta/Aguda & 101 & $99,02 \%$ \\
\hline & $\mathbf{1 0 2}$ & $\mathbf{1 0 0 , 0 0 \%}$ \\
\hline
\end{tabular}

Fonte: Dados da pesquisa.

Vê-se que quase todas as empresas, entre as que representam 23,94\% total, apresentam organograma alto/agudo, o que se justifica frente aos inúmeros cargos e funções inseridos em uma organização. Apenas uma organização, a Fleury S.A., que disponibilizou o organograma, conta com uma organização achatada, não contemplando muitos setores e níveis hierárquicos.

Posteriormente à análise da estatística descritiva das variáveis, foram analisados as significâncias, resultantes dos testes realizados entre os indícios da existência de controladoria e as características das organizações.

A Tabela 9 expõe as análises de significância estatística da relação entre os indícios sobre a existência de controladoria, que se classificam em três níveis: empresas que apenas citam que há controladoria, empresas que citam e acrescentam alguma outra informação e empresas que não reportam nada sobre a controladoria e as características das organizações:

Tabela 9 - Significância das relações entre os indícios de existência da controladoria na organização e as características da empresa

\begin{tabular}{l|c}
\hline \multicolumn{1}{c|}{ Indícios da Existência de Controladoria na Organização } & P \\
\hline Tempo de constituição & 0,6556 \\
Tempo de registro na CVM & 0,7126 \\
Receita de venda de bens e/ou serviços & $\mathbf{0 , 0 1 0 2}$ \\
Número de empregados & $\mathbf{0 , 0 0 4 9}$ \\
Número de empregados + terceirizados & $\mathbf{0 , 0 0 4 9}$ \\
Disponibilização de organograma & 0,2720 \\
Estrutura do organograma & 0,9484 \\
\hline
\end{tabular}

Fonte: Dados da pesquisa.

Na combinação de variáveis, percebeu-se que a receita de venda de bens e/ou serviços, número de empregados e o número de empregados mais terceirizados mostraram-se significantes, o que infere que tais variáveis influenciam nos indícios da existência da controladoria na organização, ou seja, na medida em que a receita de venda de bens e/ou serviços se altera, alteram-se os indícios da existência de controladoria na organização - o que acontece também com as variáveis: número de empregados e o número de empregados mais terceirizados.

Após a realização dos testes, constatou-se a significância das três variáveis evidenciadas na tabela 9. Frente a essa significância, criaram-se gráficos para melhor visualizar a relação 


\section{Contabilidade}

entre a variável de existência da controladoria, com as variáveis significativas relacionadas às características da empresa, detalhados no Gráfico 1, Gráfico 2 e Gráfico 3:

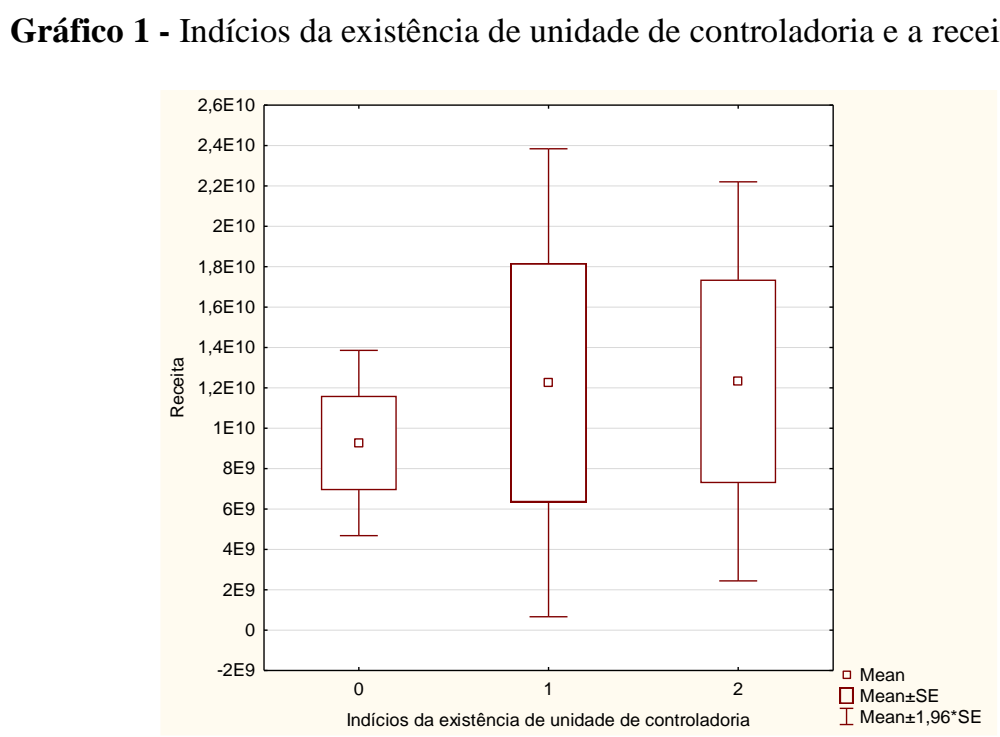

Fonte: Dados da pesquisa.

No gráfico 1, é possível observar que as empresas que apenas citam que há indício de existência da unidade de controladoria (representadas pelo grupo 0) apresentam uma menor variabilidade de receita, uma menor mediana das receitas; o grupo 2 (empresas que não reportam nada sobre a controladoria) conta com uma variabilidade moderada; enquanto que o grupo 1 , relativo às empresas que citam e falam algo sobre a unidade organizacional da controladoria, apresenta uma variabilidade de receitas e uma mediana bem maior.

Gráfico 2 - Indícios da existência de unidade de controladoria e o número de empregados 


\section{Contabilidade}

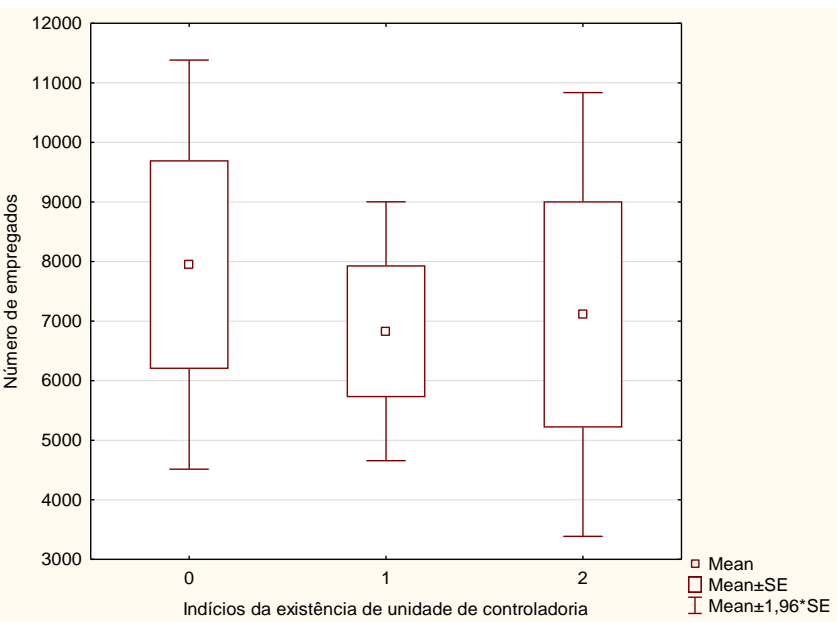

Fonte: Dados da pesquisa.

O gráfico 2 demonstra que o grupo 2, das empresas que não reportam nada sobre a controladoria, apresenta uma maior variabilidade quanto ao quantitativo do número de empregados, enquanto que o grupo 0 , das empresas que apenas citam que há controladoria, conta uma variabilidade moderada; e as empresas do grupo 1, aquelas que citam que contam com a controladoria e ainda discorrem algumas outras informações, apresentam variabilidade menor.

Gráfico 3 - Indícios da existência de unidade de controladoria e o número de empregados + terceirizados

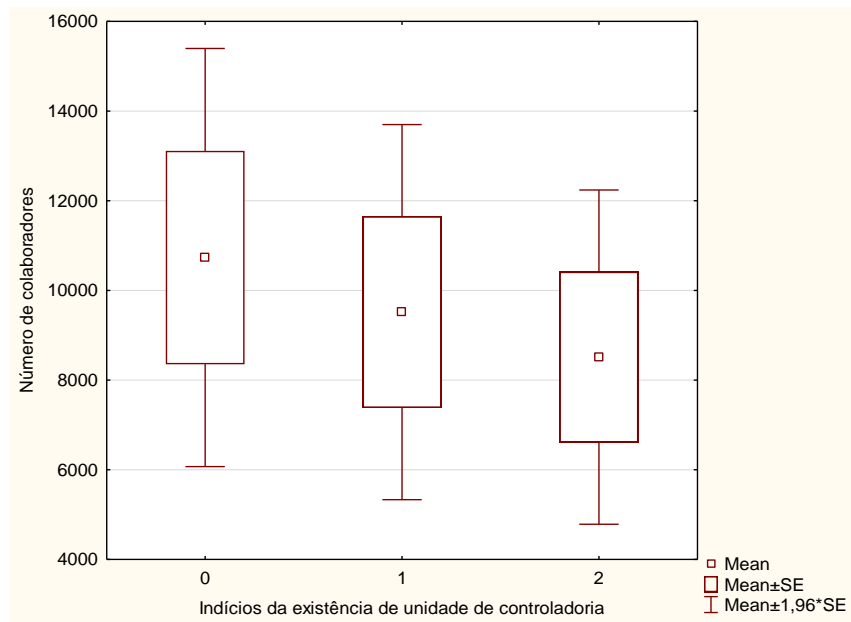

Fonte: Dados da pesquisa.

No gráfico 3, o grupo de empresas que apenas citam que há a controladoria (grupo 0) exibe variabilidade maior, enquanto que o grupo de empresas que citam e discorrem algo a mais conta com variabilidade moderada; já o grupo de empresas que não reportam nada sobre a controladoria (grupo 2) apresenta a menor variabilidade. 


\section{Revista

\section{CONCLUSÕES}

A literatura tem apontado que a controladoria está cada vez mais presente na organização, mas com os resultados da pesquisa foi possível identificar uma ausência, por parte das organizações de discorrerem sobre a controladoria.

No universo de 426 empresas, identificou-se que apenas 97 delas disponibilizam informações sobre a controladoria em seus sítios institucionais e nas noticias que divulgam. Faz-se necessário destacar a sentença anterior, pois não se pode afirmar que a organização não conta com o setor de controladoria, já que a mesma pode existir e ser difundida apenas no interior da organização.

Foram realizados testes estatísticos que identificaram significância entre a existência ou não da controladoria e a receita de venda de bens e/ou serviços, número de empregados e número de empregados + terceirizados, o que permite que se infira que pode haver uma relação positiva ou negativa entre essas variáveis.

Os autores que discorrem sobre a controladoria apresentam, de forma unânime, a sua importância e essencialidade no contexto organizacional, por isso, acredita-se que apesar de não haver informações suficientes e detalhadas sobre a controladoria no interior das organizações pesquisadas, a mesma deve contar com tal órgão, com o propósito de controlar os objetivos das organizações.

Sugere-se que novas pesquisas sejam feitas, entrando em contato com todas as empresas listadas na B3, a fim de identificar, de forma íntegra e totalitária informações sobre a controladoria.

\section{REFERÊNCIAS}

AHMADY, G. A.; MEHRPOUR, M.; NIKOORAVESH, A. Organizational Structure. Procedia - Social and Behavioral Sciences, v. 230, p. 455-462, 2016.

ALMEIDA, F. C.; MACHADO NETO, A. J.; GIRALDI, J. M. E. Estrutura e estratégia: evolução de paradigmas. Revista de Gestão, v. 13, n. 2, p. 15-26, 2006.

APPOLINÁRIO, F. Metodologia científica, São Paulo: Cengage Learning, 2016.

ARAÚJO, R. C. DE. A controladoria e a informação gerencial no processo decisório das empresas. Monografia (Especialização em Controladoria) - Universidade Federal da Paraíba. Paraíba, p. 46, 2003. 
BAPTISTA, M. N.; CAMPOS, D. C. de. Metodologias de pesquisa em ciências: análises quantitativa e qualitativa, 2. ed. Rio de Janeiro: LTC, 2018.

BARRETO, M. da G. Controladoria na gestão: a relevância dos custos da qualidade. São Paulo: Saraiva, 2008.

BELMIRO, L. A. G.; OliVEIRA, J. F. C. de; AZEVEDO, S. C. de; LAGE, J. N. Administração Estratégica, 3. ed. LTC, 2014.

BEMFICA, M. F. C. Controladoria e desempenho sustentável corporativo nas agroindústrias do setor sucroalcooleiro no Estado de Pernambuco. Dissertação (Mestrado em Controladoria). Programa de Pós-Graduação em Controladoria da Universidade Federal Rural de Pernambuco, Pernambuco, 2016.

BEUREN, I. M.; GOMES, E. do C. O.; LUZ, R. M. da. Motivações para Implantar a Área Organizacional de Controladoria em Grandes Empresas. Gestão \& Regionalidade, v. 28, n. $82,2012$.

CALlADO, A. A. C.; AMORIM, T. N. G. F. Competências da Função de Controller em Hotéis de Grande Porte da Região Metropolitana do Recife. Revista Evidenciação Contábil \& Finanças, v. 5, n. 2, p. 57-73, 2017.

CALZOLAIO, A. E.; SPRICIGO, G.; MONTEIRO, S. M. M. Da Gaveta para a Indústria: Correspondência entre Patentes Universitárias e Atividades Econômicas. Revista Gestão \& Tecnologia, v. 18, n. 1, p. 115-139, 2018.

CARREIRA, D. Organização, Sistemas e Métodos - Ferramentas para racionalizar as rotinas de trabalho e a estrutura organizacional da empresa, 2. ed. São Paulo: Saraiva, 2009.

CAVENAGHI, F. B.; PIMENTA JÚNIOR, T.; ANTÔNIO, R. M.; LIMA, F. G.; CORRÊA, A. C. C. The Behavior of Brazilian Companies Shares Return under Social Responsibility. Revista de Negócios, v. 24, n. 3, p. 49-61, 2019.

COELHO, E.; LUNKES, R. J.; MACHADO, A. O. A controladoria na hierarquia organizacional: um estudo nas maiores empresas do estado de Santa Catarina, Enfoque Reflexão Contábil, v. 31, n. 2, p. 33-46, 2012.

COSTA, M. C. F.; SOUZA, B. S. S.; FELL, A. F. A. Um estudo da estrutura organizacional e as mudanças organizacionais: proposta de um novo modelo. NAVUS - Revista de Gestão e Tecnologia, v. 2, n. 1, p. 57-74, 2012.

FÁVERO, L. P.; BELFIOR, E. P.; SILVA, F. L.; CHAN, B. L. Análise de dados: modelagem multivariada para tomada de decisões. Rio de Janeiro: Elsevier, 2009.

GIRALDELI, C. G.; PICCHIAI, D. Análise da Relação entre a Estrutura Organizacional e o Desempenho Operacional na Prestação de Serviços de TI de Alto Valor Agregado. Revista Eletrônica de Estratégia \& Negócios, v. 8, n. 3, p. 205-243, 2015. 
KELLNER, A.; RINGHOFER, S.; HEHENBERGER, P.; WEINGARTNER, L.; FRIEDL, M. The Impact on Organizational Structures of Model-based Mechatronic System Design, Procedia Technology, v. 26, p. 333-340, 2016.

LAKATOS, E. M.; MARCONI, M. de A. Metodologia científica. 7. ed. São Paulo: Atlas, 2017.

LEITE, E. G.; DIEHL, C. A.; MANVAILER, R. H. M. Práticas de Controladoria, Desempenho e Fatores Contingenciais: um Estudo em Empresas Atuantes no Brasil. Revista Universo Contábil, v. 11, n. 2, p. 85-107, 2015.

LEITE, M.; REIF, E.; LAVARDA, C. E. F. Análise da Controladoria e suas Funções: Estudo de Caso em uma Organização da Construção Civil. Desafio Online, v. 6, n. 1, p. 1-24, 2018.

LEITE, N. P.; ALBUQUERQUE, L. G. Os desafios de gerir pessoas em uma estrutura organizacional remota. Revista de Gestão, v. 16, n. 3, art. 7, p. 99-114, 2009.

LIMA, F. B. De L.; DE LUCA, M. M. M.; SANTOS, S. M.; PONTE, V. M. R. A controladoria em Instituições Financeiras: Estudo de caso no Banco do Nordeste do Brasil SA. Revista Contabilidade Vista \& Revista, v. 22, n. 1, p. 43-72, 2011.

LOURENSI, A.; BEUREN, I. M. Inserção da Controladoria em teses da FEA/USP: uma análise nas perspectivas dos aspectos conceitual, procedimental e organizacional. Contabilidade Vista \& Revista, v. 22, n. 1, p. 15-42, 2011.

MARCONI, M. de A.; LAKATOS, E. M. de. Metodologia do trabalho científico: projetos de pesquisa / pesquisa bibliográfica / teses de doutorado, dissertações de mestrado, trabalhos de conclusão de curso. 8. ed. São Paulo: Atlas, 2017.

MARCONI, M. de A.; LAKATOS, E. M. Fundamentos da metodologia científica. 8. ed. São Paulo: Atlas, 2019.

MARÔCO, J. Análise estatística com o SPSS Statistics. ReportNumber: Lda, 2011.

MEGginson, L. C.; MOSLEY, D. C.; PIETRI JR., P. H. Administração: Conceitos e Aplicações. 4. ed. São Paul: Harbra Ltda, 1998.

MINTZBERG, H.; LAMPEL, J; QUINN, J. B.; GHOSHAL, S. O processo da estratégia: conceitos, contextos e casos selecionados. Porto Alegre: Artmed, 2011.

MONTANA, P. J.; CHARNOV, B. H. Administração. 3. ed. São Paulo: Saraiva, 2010.

MORANGE, A. S.; JORGE, F. T. Controladoria: análise financeira, planejamento e controle orçamentário. São Paulo: Atlas, 2008.

NASCIMENTO, A. M.; REGINATO, L. Controladoria: um enfoque na eficácia organizacional. 3. ed. São Paulo: Atlas, 2013. 
NASCIMENTO, F. R. V.; ROSA, A. L. T.; SANTOS, S. M. D.; TENÓRIO, J. N. B. A Controladoria como suporte ao processo de gestão numa empresa do comércio varejista. Revista de Contabilidade do Mestrado em Ciências Contábeis da UERJ, v. 10, n. 2, p. 1126, 2005.

OLIVEIRA, D. de P. R. de. Sistemas, organização e métodos: uma abordagem gerencial. 21. ed. São Paulo: Atlas, 2013.

OLIVEIRA, D. de P. R. de. Estrutura organizacional: uma abordagem para resultados e competitividade. 3. ed. São Paulo: Atlas, 2014.

OLIVEIRA, L. M. de.; PEREZ JR, J. H.; SILVA, C. A. dos S. Controladoria estratégica. 11. ed. São Paulo: Atlas, 2015.

PADOVEZE, C. L. Controladoria Básica. 3. ed. São Paulo: Cengage Learning, 2013.

PADOVEZE, C. L. Controladoria estratégica aplicada: conceitos, estrutura e sistema de informações. São Paulo: Cengage Learning, 2016.

PELEIAS, I. R. Controladoria: gestão eficaz utilizando padrões. São Paulo: Saraiva, 2002.

POLITELO, L.; GUSE, J. C.; LEITE, M.; SILVA, T. P.; DORR, A. C. Uma análise em organização sob a ótica da Controladoria Empresarial. Desafio Online, v. 2, n. 1, p. 487-504, 2014.

RAMPAZZO, L. Metodologia científica: para alunos dos cursos de graduação e pós graduação. 8. ed. São Paulo: Edições Loyola, 2015.

SAMPIERI, R. H.; COLLADO, C. F.; LUCIO, M. del P B. Metodologia de Pesquisa. 5. ed. Porto Alegre: Penso, 2013.

SANTOS, N. M.; BRONZO, M.; OLIVEIRA, M. P. V.; RESENDE, P. T. V. Cultura organizacional, estrutura organizacional e gestão de pessoas como bases para uma gestão orientada por processos e seus impactos no desempenho organizacional. Brazilian Business Review, v. 11, n. 3, p. 106-129, 2014.

SCHMIDT, P; SANTOS, J. L. Fundamentos de controladoria. São Paulo: Atlas, 2009.

SCHMIDT, P.; SANTOS, J. L.; MARTINS, M. A. dos S Manual de controladoria. São Paulo: Atlas, 2014.

SILVA, E. M. da.; SILVA, E. M. da; GONÇALVES, V.; MUROLO, A. F. Estatística. 5. ed. São Paulo: Atlas, 2018.

SPIEGEL, M. R.; STEPHENS, L. J. Estatística. 4. ed. Porto Alegre: Bookman, 2009.

STONER, J.A. F.; FREEMAN, R. E. Administração. 5. ed. Rio de Janeiro: Prentice Hall do Brasil, 1985. 
TUNG, N. H. Controladoria financeira das empresas: uma abordagem prática: ampliado com metodologia de redução de custos. 10. ed. São Paulo: Edições Universidade-Empresa, 2016.

VIEIRA, S. Bioestatísticos tópicos avançados. São Paulo: Elsevier Brasil, 2011.

WILLAERT, P.; BERG, J. V. D.; WILLEMS, J.; DESCHOOLMEESTER, D. The processoriented organization: a holistic view. Developing a framework for business process orientation maturity. In: INTERNATIONAL BPM CONFERENCE, v. 5, p. 24-28 Brisbane (AUS). Anais... Brisbane: BPM, 2007. 